\title{
Investigation of Vaporized Kerosene Injection and Combustion in a Supersonic Model Combustor
}

\author{
Xuejun Fan, ${ }^{*}$ Gong Yu, ${ }^{\dagger}$ Jianguo Li, ${ }^{\ddagger}$ and Xinyu Zhang ${ }^{\S}$ \\ Chinese Academy of Sciences, 100080 Beijing, People's Republic of China \\ and \\ Chih-Jen Sung ${ }^{\text {II }}$ \\ Case Western Reserve University, Cleveland, Ohio 44106
}

\begin{abstract}
Injection and combustion of vaporized kerosene was experimentally investigated in a Mach 2.5 model combustor at various fuel temperatures and injection pressures. A unique kerosene heating and delivery system, which can prepare heated kerosene up to $820 \mathrm{~K}$ at a pressure of $5.5 \mathrm{MPa}$ with negligible fuel coking, was developed. A three-species surrogate was employed to simulate the thermophysical properties of kerosene. The calculated thermophysical properties of surrogate provided insight into the fuel flow control in experiments. Kerosene jet structures at various preheat temperatures injecting into both quiescent environment and a Mach 2.5 crossflow were characterized. It was shown that the use of vaporized kerosene injection holds the potential of enhancing fuelair mixing and promoting overall burning. Supersonic combustion tests further confirmed the preceding conjecture by comparing the combustor performances of supercritical kerosene with those of liquid kerosene and effervescent atomization with hydrogen barbotage. Under the similar flow conditions and overall kerosene equivalence ratios, experimental results illustrated that the combustion efficiency of supercritical kerosene increased approximately 10-15\% over that of liquid kerosene, which was comparable to that of effervescent atomization.
\end{abstract}

\section{Introduction}

$\mathbf{I}^{\mathrm{N}}$ $\mathrm{N}$ practical liquid-hydrocarbon-fueled scramjet operations, the most commonly adopted method to cool the engine would be regenerative cooling. The liquid fuel before being injected into the combustor is circulated through the walls of the combustor typically under high pressures of 35-70 atm (Ref. 1). It is also expected that the fuel temperature and its thermodynamic state vary with the flight Mach number and the different stages of the flight mission. ${ }^{2,3}$ In the early flight stage, the amount of heat absorbed by the fuel is minimal; the liquid-hydrocarbon fuel would remain in the liquid state before entering the combustor. As the flight speed increases, the fuel temperature rises, and the fuel can transform to the vapor phase when exceeding its bubble point. If both fuel temperature and pressure are higher than the thermodynamic critical point, the fuel becomes supercritical. Further increasing the fuel temperature beyond $750 \mathrm{~K}$ would lead to thermal decomposition of the hydrocarbons in the fuel. ${ }^{1}$

When applying liquid fuel injection, the successful operation of a scramjet engine requires the processes of fuel vaporization, fuel-air mixing, self-ignition, and complete combustion to be accomplished within a limited residence time available in the combustor. As a consequence, extensive studies have explored various flame-holding schemes for providing a high-temperature radical source in the

Presented as Paper 2004-3485 at the AIAA/ASME/SAE/ASEE 40th Joint Propulsion Conference and Exhibit, Ft. Lauderdale, FL, 11-14 July 2004; received 18 January 2005; revision received 31 May 2005; accepted for publication 6 June 2005. Copyright (C) 2005 by the American Institute of Aeronautics and Astronautics, Inc. All rights reserved. Copies of this paper may be made for personal or internal use, on condition that the copier pay the $\$ 10.00$ per-copy fee to the Copyright Clearance Center, Inc., 222 Rosewood Drive, Danvers, MA 01923; include the code 0748-4658/06 \$10.00 in correspondence with the CCC.

*Associate Professor, Institute of Mechanics, 15 Zhongguancun Road, Haidian District; xfan@imech.ac.cn.

†Professor, Institute of Mechanics; yugong@imech.ac.cn. Member AIAA.

${ }^{\ddagger}$ Professor, Institute of Mechanics; jgli@imech.ac.cn. Member AIAA.

\$Professor, Institute of Mechanics; changxy@imech.ac.cn. Member AIAA.

${ }^{\mathbb{I}}$ Associate Professor, Department of Mechanical and Aerospace Engineering; cjs15@po.cwru.edu. Senior Member AIAA. recirculation zone with minimal stagnation pressure losses, ${ }^{4-11}$ different atomization methods for achieving fast evaporation and fuelair mixing, ${ }^{12-15}$ and diverse chemical enhancements for shortening the characteristic reaction time through the use of partially cracked hydrocarbon fuels, ${ }^{16-18}$ pilot hydrogen, ${ }^{4,5,14,19-22}$ or plasma. ${ }^{23-25}$ Along these lines, we have systematically examined the effects of injection strategy, pilot hydrogen, and cavity geometry on the performance of various liquid-kerosene-fueled model combustors. ${ }^{26,27}$ It was also shown that a higher level of atomization can be achieved by using effervescent atomization, which can further promote the overall burning of kerosene in a supersonic airflow. ${ }^{27,28}$

As discussed earlier, with the use of regenerative cooling the liquid fuel could be vaporized before reaching the fuel injector. Even before the temperature is sufficiently high for the fuel to thermally react, the changes in thermophysical properties of the fuel, from saturated liquid to supercritical fluid, are expected to significantly affect the fuel injection process and the subsequent fuel-air mixing and combustion inside the supersonic combustor. Specifically, in the supercritical region the fuel exhibits liquid-like density, gas-like diffusivity, and pressure-dependent solubility. ${ }^{29}$ As such, during injection the supercritical fuel can be directly transformed to the gaseous state corresponding to the local combustor condition. Either being supercritical or subcritical, one apparent benefit utilizing vaporized fuel injection is to bypass the atomization and vaporization processes. As a result, the overall fuel-air mixing could be enhanced. This would also in turn expand the combustion stability range by promoting self-ignition and extending the extinction limits.

Recognizing that experimental investigation involving the use of vaporized hydrocarbon injection in a supersonic model combustor with flame-holder cavities is meager, the present study aims to extend our previous endeavors on liquid-kerosene combustion in supersonic crossflows to assess the combustor performance with vaporized kerosene injection through systematic experimental characterizations. The effects of the changes in the fuel states on fuel injection process, self-ignition limit, and combustion efficiency of a kerosene-fueled supersonic model combustor were examined. A unique fuel delivery and injection system that covered a wide range of fuel injection modes, varying from liquid atomization to vaporized fuel injection, was also developed to carry out the experiments.

To accurately determine the flow rate of supercritical-pressure, high-temperature kerosene vapor and to control the fuel conditions 